\title{
EFEKTIFITAS APLIKASI RDBMS SEBAGAI MEDIA ARSIP DATA PADA KANTOR KESEHATAN PELABUHAN PEKANBARU BERBASIS ONLINE
}

\author{
Bayu Febriadi' ${ }^{1}$, Ahmad Zamsuri² \\ Prodi Sistem Informasi Fakultas Ilmu Komputer Universitas Lancang Kuning \\ Jl. Yos Sudarso KM. 8 Rumbai, Pekanbaru, Riau \\ bayufebriadi9@gmail.com
}

\begin{abstract}
Kantor Kesehatan Pelabuhan Kelas II Pekanbaru is a government office that concerns about healthy, especially about environment health. There is a problem in case of saving electronic data, also in analyzing daily data both for internal and external data. The office has some computers and other tools that are useful in saving electronic data. In fact, the data are still saved in available cupboards and it is not efficient for an important data that is analyzed for more than one time. In other words, it is not good for a data is needed to be analyzed continuously. Rational Data Base Management System (RDBMS) application is an online based saving data and it uses System Development Life Cycle (SDLC) method. Hopefully, the application will be very useful for employees Kantor Kesehatan Pelabuhan Pekanbaru in managing their work.
\end{abstract}

Keywords: RDBMS, Data, Kantor Kesehatan Pelabuhan Kelas II Pekanbaru.

\begin{abstract}
Abstrak
Kantor Kesehatan Pelabuhan Kelas II Pekanbaru merupakan Kantor pemerintahan yang bergerak dibidang kesehatan khususnya mengenai lingkungan. Adapun yang menjadi kendala pada kantor kesehatan pelabuhan kelas II pekanbaru adalah belum adanya penyimpan data elektronik dalam pengolahan data harian baik data internal dan data eksternal, sementara pengadaan komputer dan sumber daya sudah ada, sehingga data olah harian kegiatan masih disimpan dalam bentuk lembaran kertas di lemari gudang kantor, dimana hal ini tidak efisien untuk pengolahan data yang berulang-ulang apabila suatu saat memerlukan data untuk ditampilkan kembali apabila data ini hilang atau terjadi kerusakan terhadap data ini. Dengan penggunaan aplikasi relational database management system (RDBMS) dalam penyimpanan data berbasis online dan menggunakan metode System Development Life Cycle (SDLC) dalam tahapan penyelesaian masalah, diharapkan membantu pihak kantor kesehatan pelabuhan pekanbaru dalam menjalankan kegiatan harianya.
\end{abstract}

Kata kunci: RDBMS, Data, Kantor Kesehatan Pelabuhan kelas II pekanbaru.

\section{PENDAHULUAN}

Kantor Kesehatan Pelabuhan Pekanbaru merupakan Kantor pemerintahan yang bergerak dibidang kesehatan khususnya mengenai lingkungan. Dalam kegiatan nya saat ini pengolahan data register jemaah umrah dalam pengurusan vaksin masih dicatat dilembaran kertas, sehingga hal ini sangat menggangu dalam kegiatan harian pada kantor kesehatan 
pekanbaru apabila pengolahan data untuk pencetakan laporan dan dalam perhitungan data begitupun untuk back up data apabila diperlukan kembali data register jemah umrah dalam pengurusan vaksin. Sementara pengadaan komputer dan sumber daya sudah ada pada kantor KKP kelas II pekanbaru. Sistem informasi yang berbasis web juga dapat menjadi sarana promosi yang efesien dan sumber informasi yang dapat diakses oleh pengguna internet yang semakin lama semakin luas. dimana pemanfaatan sistem informasi berbasis komputer sangat membantu dalam kegiatan sehari-hari. Relationship Database Management System (RDBMS) merupakan suatu penyusunan data yang terstruktur yang disimpan dalam media pengingat (harddisk) yang tujuanya adalah agar data tersebut dapat diakses dengan mudah dan cepat[14].

Setelah dilakukan analisa di Kantor Kesehatan Pelabuhan Pekanbaru penulis menemukan beberapa permasalahan yang harus segera dibenahi diantaranya.

a. Belum adanya penyimpan data elektronik sementara pengadaan komputer dan sumber daya sudah ada, sehingga data olah harian kegiatan masih disimpan dalam bentuk lembaran kertas dimana hal ini tidak efisien untuk pengolahan data yang berulang-ulang apabila suatu saat memerlukan data untuk ditampilkan kembali apabila data ini hilang atau terjadi kerusakan terhadap data ini.

b. Belum adanya sistem yang terintegrasi dengan baik dalam arsip data pekanbaru sehingga hal ini sangat menyulitkan dalam melakukann kegiatan harian.

\section{METODOLOGI PENELITIAN}

Pada metode penelitian akan dijelaskan tahapan dalam penyeesaiaan masalah dari kegiatan yang akan dilakukan untuk mencapai tujuan yang telah ditetapkan, dapat dilihat pada gambar 1 dibawah ini

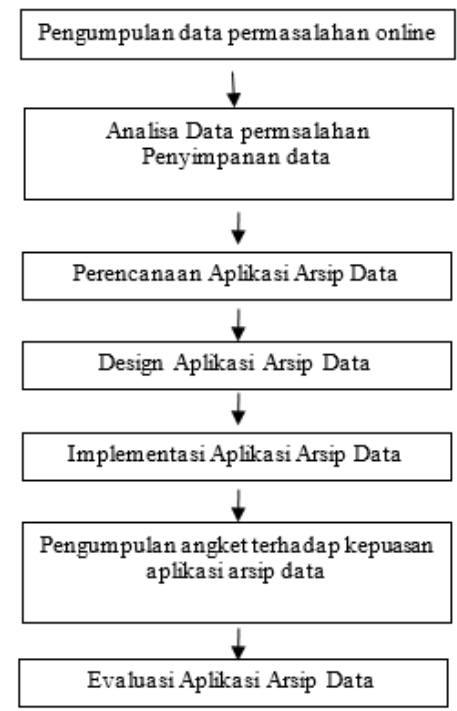

Gambar 1. Metode Penelitian 
Dari gambar dijelaskan secara rinci kegiatan penelitian yang dilakukan dari pengumpulan dan menganalisa permasalahan sampai tahapan penyelesaian terhadap masalah dalam penyimpanan data pada kantor kesehatan pelabuhan pekanbaru.

\section{HASIL DAN PEMBAHASAN}

Sebelum memulai kegiatan, penulis telah mengumpulkan data angket terhadap pengolahan data yang oleh karyawan kantor kesehatan pelabuhan kelas II pekanbaru yang di isi oleh masyarakat yang mengurus international certificate vaccine (ICV), dimana diambil sampel data dalam satu minggu terakhir.

Tahapan perancangan system yang digunakan adalah dengan metode unified modelling language (UML) [5-7].

1. Usecase Diagram

Pada perancangan sistem yang akan dibangun activity diagram dapat dilihat pada gambar 2 dibawah ini.

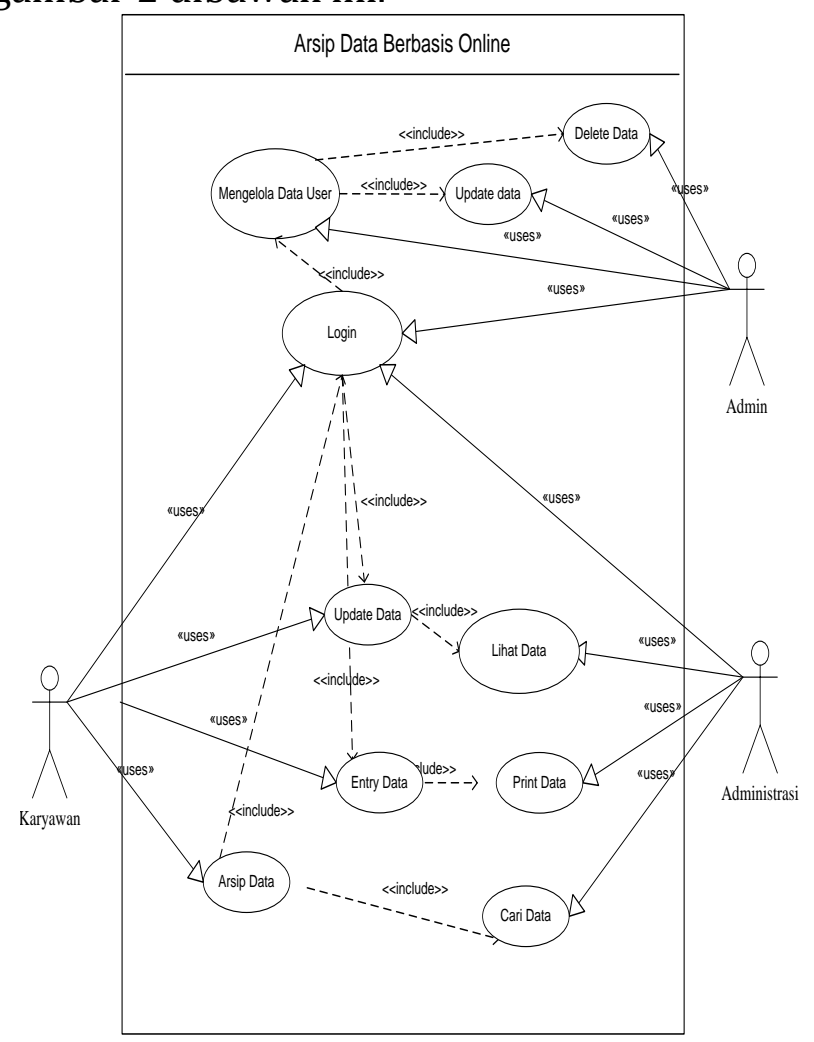

\section{Activity Diagram}

Gambar 2. Usecase Diagram

Pada perancangan sistem yang akan dibangun activity diagram dapat dilihat pada gambar 3 dibawah ini. 


\section{Class Diagram}

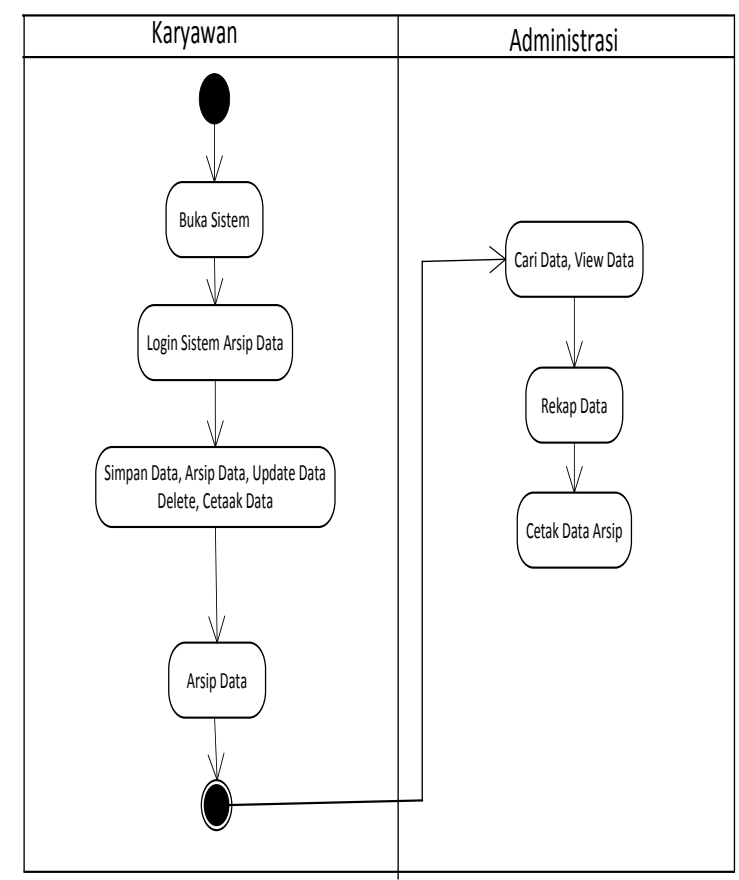

Gambar 3. Activity Diagram

Pada perancangan sistem yang akan dibangun class diagram dapat dilihat pada gambar 4 dibawah ini.

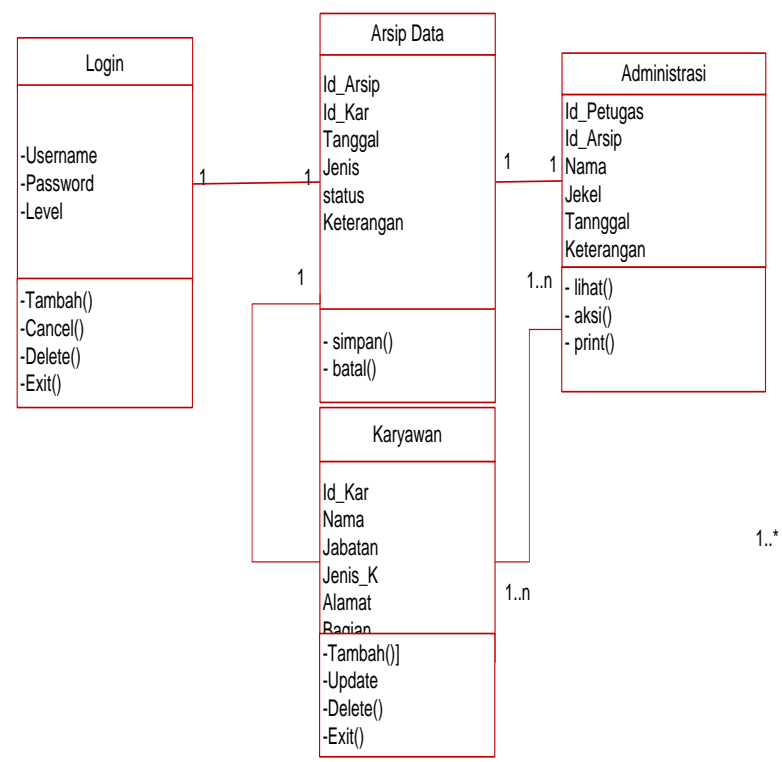

\subsection{Hasil}

\section{Gambar 4. Class Digram}

Setelah aplikasi yang telah dibangun di implementasikan pada kantor kesehatan pelabuhan pekanbaru, maka penulis mengumpulkan data angket terhadap kepuasan aplikasi arsip data kepada karyawan yang menggunakan aplikasi dalam pengolahan data 


\begin{tabular}{|c|c|c|c|c|c|c|c|c|c|c|c|}
\hline & $\mathbf{1}$ & $\mathbf{2}$ & $\mathbf{3}$ & $\mathbf{4}$ & $\mathbf{5}$ & $\mathbf{6}$ & $\mathbf{7}$ & $\mathbf{8}$ & $\mathbf{9}$ & $\mathbf{1 0}$ & Jlh \\
\hline 1 & 5 & 4 & 3 & 4 & 4 & 4 & 5 & 5 & 3 & 3 & 59 \\
\hline 2 & 5 & 5 & 5 & 4 & 5 & 5 & 5 & 5 & 4 & 4 & 68 \\
\hline 3 & 5 & 5 & 5 & 5 & 5 & 5 & 5 & 4 & 4 & 5 & 66 \\
\hline 4 & 4 & 4 & 4 & 4 & 4 & 4 & 4 & 4 & 1 & 1 & 51 \\
\hline 5 & 5 & 5 & 4 & 5 & 4 & 4 & 4 & 4 & 3 & 3 & 59 \\
\hline 6 & 5 & 4 & 5 & 5 & 4 & 5 & 5 & 4 & 3 & 3 & 60 \\
\hline 7 & 5 & 4 & 5 & 5 & 4 & 5 & 5 & 4 & 3 & 3 & 60 \\
\hline 8 & 4 & 3 & 4 & 4 & 4 & 4 & 4 & 4 & 1 & 1 & 49 \\
\hline 9 & 5 & 4 & 5 & 5 & 3 & 5 & 4 & 4 & 4 & 4 & 63 \\
\hline 10 & 4 & 4 & 5 & 5 & 4 & 5 & 5 & 5 & 3 & 4 & 63 \\
\hline 11 & 5 & 4 & 5 & 5 & 5 & 5 & 5 & 5 & 3 & 4 & 68 \\
\hline 12 & 5 & 4 & 5 & 5 & 4 & 5 & 3 & 5 & 3 & 3 & 60 \\
\hline 13 & 5 & 4 & 5 & 5 & 4 & 5 & 5 & 4 & 2 & 2 & 53 \\
\hline 14 & 5 & 4 & 4 & 4 & 3 & 5 & 5 & 4 & 3 & 3 & 53 \\
\hline 15 & 5 & 4 & 5 & 5 & 5 & 5 & 5 & 4 & 3 & 3 & 61 \\
\hline $\mathrm{T}$ & 88 & 78 & 86 & 87 & 76 & 88 & 87 & 81 & 54 & 59 & 111 \\
\hline $\mathrm{M}$ & 5 & 4 & 5 & 5 & 4 & 5 & 5 & 4 & 3 & 3 & 59 \\
\hline
\end{tabular}

Dari tabulasi di atas didapatkan perhitungan mean (rata-rata) dengan nilai 59 dalam arti bahwa peserta rata-rata mengetahui dan puas dengan aplikasi RDBMS sebagai media Pengolahan data elektronik. Jika dibandingkan dengan awal survey, dapat dilihat adanya peningkatan animo peserta untuk menggunakan aplikasi RDBMS sebagai pengolahan data elektronik.

\section{SIMPULAN}

Hasil dari evaluasi dari aplikasi arsip data pada kantor kesehatan pelabuhan pekanbaru, maka diperoleh kesimpulan bahwa :

a. Aplikasi arsip data yang dilaksanakan sesuai dengan tujuan yang ingin dicapai yaitu meningkatkan dalam pengolahan data dengan memanfaatkan aplikasi RDBMS pada pengolahan data elektronik untuk Nilai rata-rata sebesar 59 Point dari sebelum penerapan sistem 42 point.

b. Perancangan dengan metode Unified modelling language (UML) sangat membatu pengembang dalam membangun aplikasi arsip data.

\section{DAFTAR PUSTAKA}

[1] Barthos, Basir. 2009 Manajemen kersipan Yogyakarta: Andi Offset

[2] Hanson. 2000. Sejarah Pemograman berbasis Web. Yogyakarta: Andi offset

[3] Hardjono. 2006. Pengenalan Sistem Informasi Berbasis Web. Jakarta: Erlangga 
[4] Kadir, Abdul. 2005. Pengenalan Sistem Informasi. Jakarta, Yogyakarta: Andi

[5] Liang Gie.2000, Administrasi perkantoran Modern. Bandung: Informatika

[6] Nugroho, Andi.2004. Database Berbasis DBMS dalam Pengolahan Data Terintegrasi. Bandung: Informatika

[7] Oneto, Erima. 2008. Cascadading Management Style Sebagai media Program Berbasis Web. Bandung: Informatika 